\title{
Approach to Creating an Animal Model for Autoimmune Inflammatory Polyneuropathies
}

\author{
Wenhui Hu${ }^{1}$ and Jin Jun Luo ${ }^{2 *}$ \\ ${ }^{1}$ Department of Neuroscience, Temple University School of Medicine, Philadelphia, PA 19140, USA \\ ${ }^{2}$ Departments of Neurology and Pharmacology, Temple University School of Medicine, Philadelphia, PA 19140, USA
}

Autoimmune-mediated neuropathies result from dysfunction of the immune system triggered by an environmental invading as "immune-mimicry". The immune responses directed towards the infecting organisms cross-react with components of the peripheral nervous system (PNS). Autoimmune-mediated neuropathies can be classified into acute and chronic categories [1]. The acute inflammatory demyelinating polyneuropathy (AIDP), known as GuillainBarré syndrome (GBS), and chronic inflammatory demyelinating polyneuropathy (CIDP) are comprised of a number of variants or subtypes. The manifestations of demyelinating and axonal subtypes have been suggested to depend on the primary targets of the immune responses. GBS is characterized by inflammation of nerve roots and peripheral nerves causing acute flaccid paresis with a nadir at 2-4 weeks. CIDP, which can in some ways be considered the chronic equivalent of AIDP, is characterized by progressive and/or relapsing polyneuropathy with a course more than 2 months.

An animal model is a useful tool in the study of the pathogenesis and for establishing therapeutic strategies for treatment of the disease. Attempting to create an animal model for GBS has been made over the last 50 years [1]. A variety of antigens, including peripheral nerve myelin and its components, have been tested for the immunological responses against peripheral nerves in various species [1-3]. A reproducible animal model with clinical, pathological and neurophysiologic features similar to AIDP can be created [4,5].

It has long been recognized that myelin of the PNS differs in its composition from that of the central nervous system (CNS). For example, sphingomyelin is present in higher proportions in the peripheral spinal roots while cerebroside (including cerebroside sulphate) is higher in the CNS myelin [6]. Myelin isolated from the PNS contains various components including $170 \mathrm{KDa}$ glycoprotein, myelin associated glycoprotein, 2',3'-cyclic nucleotide-3'-phosphodiesterase, myelin protein-zero $(\mathrm{P} 0)$, myelin basic protein with molecular weights of $21.5,18.5,17,14$ and $19 \mathrm{kDa}$, myelin protein 22 and P2. It is well known that P0 is a Schwann cell-myelin specific protein with a molecular weight of $30 \mathrm{kDa}$. P0 accounts for more than $60 \%$ of the total protein of PNS myelin [7,8], and is absent in the CNS [9]. The function of P0 is not completely known but it is postulated that P0 is involved in the functional and structural stabilization of peripheral nerve myelin $[9,10]$. Because of its abundant presence in the PNS and absence in the CNS, P0 has been widely used to create an animal model of experimental autoimmune neuritis [11-18].

In this issue of JNN, Xia and his colleagues presented their study of "Isolation, purification and verification of peripheral nerve myelin derived from bovine cauda equine". Currently the available protocols or methods for obtaining a "pure" native myelin and its key components remain tedious and laborious. Xia and his colleagues combined and modified several simple protocols in order to obtain relatively pure native myelin from PNS to produce a reliable mouse model for autoimmune inflammatory polyneuritis.

In Xia's paper, the lipid, protein and glycol components of the isolated myelin were analyzed by using multiple simplified methods. The protein components of bovine peripheral nerve myelin were determined according to the known molecular weights using standard SDS-PAGE stained with Coomassie brilliant blue G. However, specific antibodies against bovine PNS and CNS myelin proteins are not readily available. The recombinant corresponding proteins should have been used to validate the predicted protein components in the isolated myelin. Drawbacks of this paper include the lack of literature review on the efficiency of the purified myelin proteins in producing experimental autoimmune neuritis. Discussion on using variant components from the PNS myelin in creating an animal model was essentially missing. For example, P0 peptide has been widely reported to induce experimental autoimmune neuritis in mice [11-15] and rats [16-18]. In addition, gangliosides which are structural components of plasma membranes and particularly abundant in the nervous system, antiganglioside antibodies, and "ganglioside mimicry" as one of the possible etiological causes in the development of GBS were not discussed. Nevertheless, this paper provides its value towards the approach to creating an animal model for autoimmune inflammatory polyneuropathies.

\section{References}

1. Meyer zu Horste G, Hartung HP, Kieseier BC (2007) From bench to bedsideexperimental rationale for immune-specific therapies in the inflamed peripheral nerve. Nat Clin Pract Neurol 3: 198-211.

2. Gold R, Hartung HP, Toyka KV (2000) Animal models for autoimmune demyelinating disorders of the nervous system. Mol Med Today 6: 88-91.

3. Pollard JD, Armati PJ (2011) CIDP - the relevance of recent advances in Schwann cell/axonal neurobiology. J Peripher Nerv Syst 16: 15-23.

4. Xia RH, Yosef N, Ubogu EE (2010) Selective expression and cellular localization of pro-inflammatory chemokine ligand/receptor pairs in the sciatic nerves of a severe murine experimental autoimmune neuritis model of GuillainBarre syndrome. Neuropathol Appl Neurobiol 36: 388-398.

5. Fricker B, Muller A, RenéF (2008) Evaluation tools and animal models of peripheral neuropathies. Neurodegenerative Dis 5: 72-108.

*Corresponding author: Jin Jun Luo, Departments of Neurology and Pharmacology, Temple University School of Medicine, 3401 North Broad Street, Suite C525, Philadelphia, PA 19140, USA, Tel: 1-215-707-3040; Fax: 1-215-707-8235; E-mail: jluo@temple.edu

Received April 12, 2012; Accepted April 12, 2012; Published April 16, 2012

Citation: Hu W, Luo JJ (2012) Approach to Creating an Animal Model for Autoimmune Inflammatory Polyneuropathies. J Neurol Neurophysiol 3:e106. doi:10.4172/2155-9562.1000e106

Copyright: @ $2012 \mathrm{Hu}$ W, et al. This is an open-access article distributed under the terms of the Creative Commons Attribution License, which permits unrestricted use, distribution, and reproduction in any medium, provided the original author and source are credited. 
Citation: Hu W, Luo JJ (2012) Approach to Creating an Animal Model for Autoimmune Inflammatory Polyneuropathies. J Neurol Neurophysiol 3:e106. doi:10.4172/2155-9562.1000e106

6. O'Brien JS, Sampson EL, Stern MB (1967) Lipid composition of myelin from the peripheral nervous system. Intradural spinal roots. J Neurochem 14: 357-365.

7. Poduslo JF, Yao JK (1985) Association and release of the major intrinsic membrane glycoprotein from peripheral nerve myelin. Biochem J 228: 43-54.

8. Greenfield S, Brostoff S, Eylar EH, Morell P (1973) Protein composition of myelin of the peripheral nervous system. J Neurochem 20: 1207-1216.

9. Sakamoto Y, Kitamura K, Yoshimura K, Nishijima T, Uyemura K (1987) Complete amino acid sequence of $\mathrm{PO}$ protein in bovine peripheral nerve myelin. J Biol Chem 262: 4208-4214.

10. Lemke G, Axel R (1985) Isolation and sequence of a cDNA encoding the major structural protein of peripheral myelin. Cell 40: 501-508

11. Miyamoto K, Miyake S, Schachner M, Yamamura T (2003) Heterozygous null mutation of myelin P0 protein enhances susceptibility to autoimmune neuritis targeting P0 peptide. Eur J Immunol 33: 656-665

12. Zhang HL, Azimullah S, Zheng XY, Wang XK, Amir N, et al. (2012) IFN-gamma deficiency exacerbates experimental autoimmune neuritis in mice despite a mitigated systemic Th1 immune response. J Neuroimmunol 246:18-26.

13. Zhang HL, Mao XJ, Zhang XM, Li HF, Zheng XY, et al. (2011) APOE epsilon3 attenuates experimental autoimmune neuritis by modulating $\mathrm{T}$ cell, macrophage and Schwann cell functions. Exp Neurol 230: 197-206.

14. Brunn A, Utermohlen O, Sanchez-Ruiz M, Montesinos-Rongen M, Blau T et al. (2010) Dual role of B cells with accelerated onset but reduced disease activity in P0-induced experimental autoimmune neuritis of $\mathrm{IgH}(/)$ mice. Acta Neuropathol 120: 667-681.

15. Mao XJ, Zhang XM, Zhang HL, Quezada HC, Mix E, et al. (2010) TNF-alpha receptor 1 deficiency reduces antigen-presenting capacity of Schwann cells and ameliorates experimental autoimmune neuritis in mice. Neurosci Lett 470 : 19-23.

16. Deng YN, Zhou WB (2007) Expression of TLR4 and TLR9 mRNA in Lewis rats with experimental allergic neuritis. Neuroimmunomodulation 14: 337-343.

17. Pineda AA, Minohara M, Kawamura N, Matsushita T, Yamasaki R, et al. (2011) Preventive and therapeutic effects of the selective Rho-kinase inhibitor fasudi on experimental autoimmune neuritis. J Neurol Sci 306: 115-120.

18. Yun W, Hua-bing W, Wei-zhi W (2007) A study of associated cellmediated immune mechanisms in experimental autoimmune neuritis rats. $J$ Neuroimmunol 185: 87-94. 